\title{
Policy-Specific Information and Informal Agenda Power
}

\author{
Alexander V. Hirsch Princeton Department of Politics \\ Kenneth W. Shotts Stanford GSB
}

\begin{abstract}
In Gilligan and Krehbiel's models of procedural choice in legislatures, a committee exerts costly effort to acquire private information about an unknown state of the world. Subsequent work on expertise, delegation, and lobbying has largely followed this approach. In contrast, we develop a model of information as policy valence. We use our model to analyze a procedural choice game, focusing on the effect of transferability, i.e., the extent to which information acquired to implement one policy option can be used to implement a different policy option. We find that when information is transferable, as in Gilligan and Krehbiel's models, closed rules can induce committee specialization. However, when information is policyspecific, open rules are actually superior for inducing specialization. The reason for this surprising result is that a committee lacking formal agenda power has a greater incentive to exercise informal agenda power by exerting costly effort to generate high-valence legislation.
\end{abstract}

$\mathrm{T}$ he formal study of legislative organization was revolutionized in a series of papers by Gilligan and Krehbiel, starting with their classic 1987 paper on procedural choice. In a sharp break from the previously prevailing norm in the literature, in which committees were modeled as a means for distributing particularistic legislative spoils, Gilligan and Krehbiel developed models in which the congressional committee system is primarily a division-of-labor arrangement facilitating the production of high-quality legislation. In the models, committees are delegated the task of acquiring policy expertise for a parent chamber that cares about both ideological policy outcomes and the production of good public policy (Fenno 1973).

Gilligan and Krehbiel's models feature a hold-up problem based on Crawford and Sobel's (1982) canonical analysis of cheap talk. A committee can invest in a costly public good-information - that enhances the quality of its recommended legislation. However, once produced, information can be expropriated by other legislators to achieve their own, potentially quite different, policy goals.
By committing in advance to consider the legislation under a rule restricting amendments, the floor can enhance the committee's incentive to invest in information acquisition.

The Gilligan and Krehbiel models are based on a powerful but narrow notion of the common good in policymaking. In the models, legislators are uncertain about the link between policies and outcomes, and committees can acquire information about that link. When legislators are risk averse, uncertainty reduction acts as a common good "that is conceptually and mathematically distinct from distributive consequences..." (Gilligan and Krehbiel 1990, 536). In a vast body of subsequent literature, uncertainty reduction, expertise, and the common good have become essentially synonymous, regardless of whether the empirical domain is institutional design, lobbying, or delegation. ${ }^{1}$ However, for analytical tractability, most models in this tradition rely on assumptions about the nature of uncertainty and expertise that, as noted by Callander (2008), are technically restrictive, substantively nontrivial, and ill-suited to some forms of policy expertise.

Alexander V. Hirsch is Assistant Professor of Politics and Public Affairs, Princeton Department of Politics, 041 Corwin Hall, Princeton, NJ 08544 (avhirsch@princeton.edu). Kenneth W. Shotts is the David S. and Ann M. Barlow Professor of Political Economy, Stanford GSB, 655 Knight Way, Stanford, CA 94305 (kshotts@stanford.edu).

For helpful comments, we thank Scott Ashworth, Steve Callander, Keith Krehbiel, Alessandro Lizzeri, Adam Meirowitz, Alan Wiseman, and seminar audiences at Caltech, Georgetown, Harvard, Kellogg, Maryland, Ohio State, Stony Brook, APSA 2008, and MPSA 2008.

${ }^{1}$ High-profile examples from the literatures on lobbying and legislative politics include Austen-Smith (1990), Baron (2000), and Battaglini (2000). Bendor and Meirowitz (2004) review and critique delegation models.

American Journal of Political Science, Vol. 56, No. 1, January 2012, Pp. 67-83

(C) 2011, Midwest Political Science Association

DOI: $10.1111 / j .1540-5907.2011 .00538 . x$ 
With these issues in mind, we propose a valencebased model of good public policy and analyze committee specialization as the production of policy valence. The concept of valence has been used primarily in electoral models as a reduced-form representation of candidatespecific characteristics, such as charisma or competence, that appeal to all voters. ${ }^{2}$ It has also been applied in the judicial politics literature as a reduced-form representation of universally desirable opinion characteristics, such as clarity and persuasiveness (Lax and Cameron 2007). In our legislative model, valence serves as a reduced-form representation of publicly observable information generated by legislative committees about how to achieve universally desirable policy goals such as effectiveness, efficiency, or cost reduction.

Our modeling choice is motivated by the observation that congressional committees, their staff, and lobbyists exert considerable effort to craft complex legislation that must meet a number of nonspatial criteria to be successful. Among other things, policies must be coherently designed, appropriate to local circumstances, cost-effective, and practical to implement given the resources and constraints of a sprawling federal bureaucracy. These considerations, which are not spatial in nature, naturally suggest a simple model of policy valence.

The two models most similar to ours are by Londregan (2000) and Ting (2010). Londregan analyzes the institutional implications of policy valence in Chile and shows that the ability to generate high-valence policies gives the president informal agenda power, because when the president crafts a high-valence bill the only way the legislature can enjoy the valence benefits is to adopt the president's proposal. Ting focuses on bureaucratic agencies' capacity for policy implementation, analyzing a two-period principal-agent model of noncontractable investment under the threat of second-period policy changes. Although organizational capacity is not a pure valence dimension, it is valued by both the principal and the agent. A key innovation of Ting's model is that he draws a distinction between capacity that is specialized, i.e., targeted toward one specific type of policy, versus general, i.e., applicable across a wide range of policies. When investment is specialized, the agent may acquire de facto agenda power by investing in capacity to implement his favored policy.

In contrast to Londregan and Ting, we focus on intra legislative procedural choice. We apply and extend

\footnotetext{
${ }^{2}$ See Ansolabehere and Snyder (2000), Groseclose (2001), and Aragones and Palfrey (2002). Endogenous valence electoral models include Caillaud and Tirole (2002), Meirowitz and Tucker (2007), and Ashworth and Bueno de Mesquita (2009).
}

their insights in the legislative context by analyzing different forms of valence, endogenizing its production, and, most importantly, analyzing how informal valence-based agenda power interacts with formal agenda power, i.e., legislative rules. We focus in particular on the degree to which the publicly available information or valence generated by committees about how to effectively design one particular policy can be applied to design alternative policies dealing with the same issue area. We term this phenomenon information transferability.

At one extreme, legislative committees can generate expertise that is applicable to a wide range of policies dealing with the same issue area, i.e., valence is transferable. One example of transferable valence comes from the recent health care reform process: a key contribution of the bipartisan "Gang of Six" negotiating in the Senate Finance Committee was to design efficiency-increasing changes to the Medicare reimbursements system. ${ }^{3}$ The resulting information about how to achieve cost savings could have been used to help finance liberal or moderate health care reforms, or even conservative ones. A key feature of transferable valence is that when a committee exerts effort to craft high-quality legislation, it must consider the possibility that a parent chamber with different ideological objectives can expropriate this investment to achieve different policy goals.

At the other extreme, a committee can generate expertise that is only applicable to one particular policy option that the committee has worked on, i.e., valence is policy-specific or nontransferable. ${ }^{4}$ For example, during the health care reform process, the Senate Committee on Health, Education, Labor, and Pensions generated information about how to design an effective public health insurance plan. ${ }^{5}$ This information could only be applied to legislation that actually included a public plan-it was not transferable to more moderate reforms. A key feature of policy-specific valence is that when a committee expends costly effort to craft high-quality legislation, it does not need to worry about the floor expropriating its investment to improve the quality of some alternative policy option with a different ideological orientation.

To analyze how transferability affects procedural choice in legislatures, we borrow the Gilligan and Krehbiel (1987) model, but dispense with private

\footnotetext{
3 "Medicare system overhaul proposed by two senators," New York Times, April 30, 2009.

${ }^{4}$ Our distinction between transferable and policy-specific valence parallels similar distinctions made by Callander (2008) and Ting (2010) in their work on delegation.

5 "Health care vote illustrates partisan divide," New York Times, July 16, 2009.
} 
information about the link between policy choices and spatial outcomes. We first show that when valence is transferable, our model generates results analogous to the canonical model: to induce committee specialization, a parent chamber will sometimes commit to consider legislation under a closed rule. However, when valence is policy-specific our results differ dramatically. Policyspecific valence is inherently protected from expropriation regardless of the rule, and we show that closed rules actually reduce the committee's incentive to specialize. Consequently, closed rules are never optimal for the parent chamber.

The reason for this surprising result is that the committee can use policy-specific valence to exert informal agenda power and pull the policy outcome toward its ideological ideal point. Specifically, if the committee proposes a bill with a high level of policy-specific valence, then even under an open rule the floor may choose not to alter the ideological location of the bill because doing so would result in a lower-valence policy. In our model, restrictive rules and specialization are thus substitutable means for the committee to achieve the same end, and we show that the greater is the committee's formal agenda power via legislative rules, the less incentive it has to obtain informal agenda power by producing policy-specific valence.

Our results suggest that the ability to induce committee specialization with restrictive rules in the canonical model is closely tied to the transferability of information. We also extend our model to show that the parent chamber may want to appoint a committee consisting of preference outliers who place a high value on informal agenda power and are therefore more willing to specialize. Finally, at a broader level, our analysis points out the need to reconsider the nature of policy and information in political contexts.

\section{Information Expropriability}

To illustrate the rationale behind our model of committee expertise, we first revisit the canonical informational model that was developed by Crawford and Sobel (1982) and applied by Gilligan and Krehbiel. In that framework, players are assumed to be uncertain about the link between a policy $p$ and the resulting outcome $x$. A player's preferences $u_{i}(x)$ are based only on the outcome, $x$, so policies serve as potentially imperfect instruments for achieving outcomes.

The canonical model assumes without loss of generality that the mapping between policies and outcomes is a function that is determined by some unknown state of the world $\omega$, where $x=f(p, \omega)$. With considerable loss of generality, but considerable gain in analytical tractability, the model further assumes that $\omega$ is simply a number that acts as a common additive shock across policies, i.e., $x=$ $p+\omega=f(p, \omega)$. Expertise is thus equivalent to learning the value of $\omega$.

While this restrictive setup facilitates analysis, it has the peculiar feature that information is fully invertible (Callander 2008), i.e., knowledge of the outcome $x^{\prime}$ resulting from a particular policy $p^{\prime}$ enables an actor to know what outcome $x^{\prime \prime}$ will result from any other policy $p^{\prime \prime}$. The value of $\omega$ encodes all relevant knowledge of the complete mapping between policies and outcomes.

What sort of policy decision corresponds to such a model? Consider the U.S. Congress setting the defense budget at the height of the Cold War, under uncertainty about Soviet capabilities. As an approximation, assume that members of Congress are either hawks or doves. Hawks believe that overwhelming military superiority is necessary to maintain security, while doves believe that parity is sufficient. In this example, which is inspired by Krehbiel's (1991, 82-83) discussion of defense spending, a single piece of unknown information-the magnitude of Soviet capabilities-determines a legislator's preferences over all possible defense budgets, because legislator preferences are over the force gap between the countries, rather than the absolute size of the budget. If a hawkish committee under the direction of a dovish floor learns the true magnitude of Soviet capabilities, it wants to mislead the floor into believing that the force gap is enormous. The information is expropriable in the sense that, regardless of the actual level of Soviet capabilities, if the floor learns the true level it can use this knowledge to implement its dovish policy of parity.

The canonical model is natural for certain policy areas, e.g., those in which the appropriate scale of the government's response is increasing in the magnitude of a problem. For example, when Congress decided what size of fiscal stimulus to adopt in 2009, members were uncertain about the severity of the recession, and the worse the recession the larger would be each member's most preferred stimulus package. However, the $x=p+\omega$ model is ill-suited to many other forms of information, particularly those pertaining to efficiency or to coordination of various components of a complex policy. In fact, many of Krehbiel's (1991) examples of information and expertise are better described by a model of information as policy-specific valence:

- Debates over whether the Strategic Defense Initiative would work (62-63): a cost-effective, functional missile shield is a high-valence policy, i.e., everyone, even doves, would prefer it over a costly missile shield that doesn't work. 
- Reforms of the Department of Housing and Urban Development (63-64): these reforms proved to be low-valence, i.e., bad from the perspective of both liberals and conservatives, because they harmed tenants' health and safety while costing taxpayers millions of dollars.

- Reforms to improve the functioning of the federal student loan system (85-86): these reforms were high-valence, i.e., good from the perspective of politicians across the political spectrum, because they kept the system afloat, so that honest students could receive loans and taxpayers would not have to bail out lenders.

- A badly designed, i.e., low-valence, insurance program for catastrophic medical care for the elderly (93).

It is also worth noting that in many issue areas, information needed to successfully implement one policy option is not readily transferable to other policies on the same issue. For example, consider a governmentprovided health plan. If a legislator learns how to design a public option that holds down costs by minimizing adverse selection, this information is not useful to a legislator designing a single-payer system in which adverse selection is irrelevant. And it surely is useless to a libertarian working to design a fully privatized market. Nonetheless, conditional on providing a public option everyone would prefer a well-designed policy that holds down costs rather than a poorly designed one. Hence, a model of policy-specific valence is appropriate for studying information in this empirical domain.

Before we turn to our analysis of legislative procedures, we note that a model of policy-specific valence is a natural way to study how expertise affects multiple aspects of policy making. For example, variation in legislators' participation on different issues (Hall 1996) may be explained by variation in their desire to exert informal agenda power via the production of policy-specific valence. Similarly, our model may explain why think tanks and interest groups often present highly detailed policy recommendations, including specific wording for legislation: although it is possible to interpret their actions as equilibrium signaling behavior in a cheap-talk game, their goal may well be simply to publicize well-designed, highvalence policies that promote their ideological objectives.

\section{The Model}

We develop a four-stage sequential game, played by a committee and floor in a legislature, using a sequence paralleling Gilligan and Krehbiel (1987). First, the floor commits to consider the committee's bill under a closed rule or an open rule. Under a closed rule, the committee's bill is voted on, up or down, against an exogenous status quo whereas under an open rule, the floor may offer amendments and adopt whatever policy best promotes its interests. Second, the committee chooses whether to invest in valence production and, in the case of policyspecific valence, chooses a target policy on which to invest. Third, the outcome of the committee's investment is publicly revealed, and the committee refers a bill to the floor for consideration. Fourth, the floor chooses policy under the rule that it committed to in the first stage. $^{6}$

Policy in our model has two components: the ideological location and the valence, or quality, associated with the bill. Valence is valued by all players and is simply a number $v \in[0, \infty)$, whereas ideology is a point $x \in \mathbb{R}$. Thus, each bill is a point in two-dimensional real space $b=(v, x) \in \mathbb{R}^{2}$. Players' utility over the two dimensions is additive, with

$$
U_{i}(b)=v-\lambda_{i}\left(\left|x_{i}-x\right|\right) .
$$

For each player $i \in\{f, c\}$, where $f$ denotes the floor and $c$ the committee, $\lambda_{i}(\cdot)$ is a spatial loss function defined over $[0, \infty)$, capturing the utility loss arising from movements away from a player's preferred ideological policy $x_{i}$. We assume that the loss functions are strictly increasing, strictly convex, twice differentiable, and that $\lambda_{i}(0)=\lambda_{i}^{\prime}(0)=0$. Note that quadratic preferences are a special case of our setup, with $\lambda_{i}(d)=d^{2}$. Without loss of generality we assume the floor median's ideal point is $x_{f}=0$ and the committee's ideal point is $x_{c}>0$. We also assume that the status quo policy $q$ has valence 0 .

Because utility from valence is linear and additive, our setup precludes interactions between ideology and valence. For example, we cannot accommodate the notion that a liberal legislator prefers that a conservative policy be low quality because she hopes it will produce bad effects and later be altered to a more ideologically appealing policy. As in other valence models, valence is by definition valued by everyone. The meaning of valence depends on the particular context. For example, it may represent cost savings that do not affect the ideological

\footnotetext{
${ }^{6}$ The Gilligan and Krehbiel model sequence does not reflect the usual sequence of events in Congress, where rules are granted after committees design bills. Although Diermeier (1995) provides a justification for procedural commitment, it is reasonable to criticize this assumption. However, our most interesting results do not depend on this assumption, because with policy-specific valence the floor does not commit to a closed rule, even if it can do so.
} 
outcome of a policy; it also could represent any other nonideological Pareto improvement in the quality of a policy. ${ }^{7}$

As in Gilligan and Krehbiel (1987), only the committee has the ability to engage in costly investment. However, the product of that investment is valence rather than knowledge of an unknown state of the world $\omega$. Our model contains no private information, and the committee's investment decision is publicly observable. The valence return is ex ante uncertain to both the committee and the floor and, once revealed, is public information.

The valence production process is as follows. First, the committee selects the target policy $\tilde{x} \in \mathbb{R}$. In the case of policy-specific valence, any information the committee subsequently acquires will be tailored toward implementing $\tilde{x}$. Next, the committee decides whether to invest in costly specialization. If the committee does not invest, the valence of the target policy is 0 . If it invests, the committee pays an up-front fixed cost $c$ and receives a probabilistic valence return $\tilde{v}$ from a distribution $F(\cdot)$ with density $f(\cdot)$. For simplicity we assume that valence returns may only be positive and that all positive returns are possible; specifically $F(\cdot)$ is continuous, equal to 0 over $(-\infty, 0]$, and strictly increasing over $[0,+\infty)$. We also assume that $F(v)$ has a finite expectation $E[v]<\infty$ and a nondecreasing hazard rate $\frac{f(\cdot)}{1-F(\cdot)}$. The last assumption is satisfied by many standard distributions, such as the exponential, and is only a sufficient, not necessary, condition for our results.

Once the committee observes the valence realization $\tilde{v}$, it can revisit its choice of policy before referring a bill to the floor. However, the consequences of bill revision depend on the transferability of valence, which is exogenous. We model two alternative forms of valence. In the first, valence generated in committee can be applied to all policies. Hence, it is transferable, and if the committee rewrites (or the floor amends) the bill to implement an alternative spatial policy $x^{\prime} \neq \tilde{x}$ it retains $\tilde{v}$. The nature of valence in the transferable game is analogous to the $p+\omega$ model, where knowledge of $\omega$ enables a decision maker to implement any desired outcome. The second form of valence is policy-specific, i.e., the return generated by the committee's investment is tailored exclusively to the target policy. The valence $\tilde{v}$ cannot be transferred to

\footnotetext{
${ }^{7}$ Valence could also be interpreted as reduction in variance in a purely spatial model with quadratic preferences. Transferable valence would be a shock reduction that applies to any policy, whereas policy-specific valence would be a shock reduction that applies only to one specific policy $\tilde{x}$. We thank an anonymous referee for this observation.
}

other policies, and if the committee rewrites the bill to implement $x^{\prime} \neq \tilde{x}$, the resulting bill has zero valence. ${ }^{8}$

Under an open rule and absent the opportunity for valence production, the unique equilibrium outcome is simply the floor's ideal point. Under a closed rule, the outcome depends on the location of the status quo policy $q$. We consider the case where $x_{f}=0<q \leq x_{c}$, i.e., the status quo is in the Pareto set between the committee and the floor. The unique Subgame Perfect Nash Equilibrium (henceforth, "equilibrium") outcome that prevails in the Romer and Rosenthal (1979) closed-rule agenda-setter model absent valence is simply gridlock. ${ }^{9}$

\section{Preview of Results}

For each variant of our model-transferable and policyspecific valence-we characterize equilibrium policy outcomes, committee investment decisions, and floor rule choices. Equilibria are unique up to these characteristics and are solved by backward induction. We specify and compare policy outcomes in four cases: valence is either transferable or policy-specific, and the rule can be either open or closed. Here we give a brief overview of our results.

Both the floor's rule choice and the up-front cost of valence investment influence the committee's incentive to invest in valence production. Our first key result is that when valence is transferable, the committee's incentive to invest under a closed rule is greater than under an open rule. In the canonical model, this effect arises because the protection afforded by closed rules results in more efficient information transmission. In our model, the transferability of valence makes a closed rule necessary for the committee to exert informal agenda power using highvalence policies, because under an open rule the floor simply expropriates any valence generated in committee and attaches it to its most preferred ideological policy.

\footnotetext{
${ }^{8}$ Having introduced our model of valence, we have three brief comments on technical details: (1) as shown in the Supplemental Appendix, our substantive results hold if the status quo has valence $v_{q}>0,(2)$ our analysis is largely unchanged if the valence distribution $F(\cdot)$ has a point mass at 0 , and (3) the assumption that zero-valence policies are always available implies that it suffices to consider valence distributions with positive support, because negative valence returns can be freely discarded.

${ }^{9}$ The case $-x_{c}<q \leq 0<x_{c}$ is identical, because the committee's most preferred policy among those that it can enact under a closed rule is $-q$, which is between 0 and $x_{c}$. Similarly, standard agendasetting models imply that the cases where $0<x_{c}<q$ or $q \leq-x_{c}<$ $0<x_{c}$ are identical to the case of $q=x_{c}$.
} 
TABLE 1 Results

Transferable Valence

Cost of Investment

\begin{tabular}{ll}
\hline Low & Always invest under either rule \\
Intermediate & Invest under closed but not under open
\end{tabular}

High

Policy-Specific Valence

Cost of Investment

Never invest under either rule
Floor Rule Choice

Open

Closed if valence benefit

exceeds ideological cost Open

\begin{tabular}{lll}
\hline Low & Always invest under either rule & Open \\
Intermediate & Invest under open but not under closed & Open \\
High & Never invest under either rule & Open \\
\hline
\end{tabular}

For intermediate costs of specialization, a closed rule is necessary and sufficient to induce committee investment. This property is a key part of the standard informational rationale for closed rules, because closed rules result in noncentrist ideological outcomes. Due to this property, equilibrium behavior in the transferable valence variant of our model is similar to Gilligan and Krehbiel's (1987) results, as seen in the top half of Table $1 .^{10}$

When the cost of investment is intermediate and the floor's choice of rule affects the committee's investment decision, the floor selects a closed rule only if the valence gains are sufficiently attractive and the committee is sufficiently moderate. This pattern arises because extreme committees use formal agenda power more aggressively, resulting in greater ideological losses for the floor. We show in Proposition 1 how the floor weighs valence benefits against ideological costs when deciding whether to adopt a closed rule.

When valence is policy-specific, the equilibrium is dramatically different. Our key result, Proposition 3, is that a committee's incentive to invest in valence is stronger under an open rule than under a closed rule. As a consequence, with policy-specific valence the floor always selects an open rule (Proposition 4). This pattern of behavior, summarized in the bottom half of Table 1, stands in stark contrast to both our transferable valence game and the Gilligan and Krehbiel model.

The underlying reason for this result is that the committee can use policy-specific valence to exercise informal agenda power under either rule. For example, under an open rule, if the committee produces a bill with a high

\footnotetext{
${ }^{10}$ Krishna and Morgan (2005) characterize a closed-rule equilibrium that Pareto-dominates the one characterized by Gilligan and Krehbiel. However, as pointed out by Krehbiel (2005), this result of Krishna and Morgan's "strengthens the informational rationale for restrictive rules" in the $x=p+\omega$ model with a single committee.
}

level of policy-specific valence, the floor may be unwilling to amend the bill because doing so would result in a loss of the valence benefits from the committee's investment. Thus, preventing expropriation no longer requires a closed rule. In fact, closed rules and valence are substitutable means for exercising agenda power, and the agenda power conferred by a closed rule reduces the marginal ideological rents that the committee can extract with valence, thereby decreasing its incentives to invest. $^{11}$

Notation. Before presenting our results we first introduce some notation. Recall that $\lambda_{f}(\cdot)$ is the floor's spatial loss function over the ideology dimension. Define $\bar{v}(x ; q)$ as

$$
\bar{v}(x ; q)=\lambda_{f}(|x|)-\lambda_{f}(|q|) .
$$

So $\bar{v}(x ; q)$ is the level of valence that makes the floor indifferent between a bill $(\bar{v}(x ; q), x)$ and the status quo $(0, q)$. Note that $\bar{v}(x ; q)$ inherits most of the properties of $\lambda_{f}(\cdot)$; in particular, it is increasing and convex in $x$.

Let $\bar{x}(v ; q)$ be implicitly defined as the unique ideological location greater than $x_{f}$ such that

$$
v=\lambda_{f}(|\bar{x}(v ; q)|)-\lambda_{f}(|q|) .
$$

Given a level of valence $v$, the floor is indifferent between a bill $(v, \bar{x}(v ; q))$ and $(0, q)$. Hence $(v, \bar{x}(v ; q))$ is the most extreme bill with valence $v$ that the floor weakly prefers to the status quo. Clearly $\bar{x}(v ; q)$ is increasing in $v$, i.e., the floor is willing to accept more ideologically extreme bills the greater is the attached valence.

\footnotetext{
${ }^{11}$ The idea that an actor without formal authority can achieve informal authority by learning about consequences is found in Aghion and Tirole's (1997) analysis of delegation. Our work differs substantially in that we use a valence-based modeling technology and apply our model to legislative procedural choice in a spatial model of policy.
} 
In each subgame, the committee's investment decision can be characterized by a unique cost cutpoint such that the committee chooses to invest in valence if and only if $c$ is below this cutpoint. Higher cutpoints imply greater incentives to invest. We write $c_{c l}^{t}\left(x_{c}, q\right), c_{o}^{t}\left(x_{c}\right), c_{c l}^{n t}\left(x_{c}, q\right)$, and $c_{o}^{n t}\left(x_{c}\right)$ to denote the cutpoints-subscripts refer to the rule (closed or open) and superscripts refer to the type of valence (transferable or nontransferable). In the case of policy-specific valence, to fully describe the committee's strategy it is also necessary to describe the committee's choice of a target policy, which we write as $\tilde{x}^{c l}\left(x_{c}, q\right)$ and $\tilde{x}^{o}\left(x_{c}\right)$ for a closed and open rule, respectively.

\section{Transferable Valence}

We first solve our transferable valence game for the case where the floor chooses an open rule. We then solve the closed-rule case and determine the floor's optimal rule choice.

Open Rule. The case of transferable valence under an open rule is straightforward. In the final stage of the game, regardless of the valence attached, the floor will amend any bill $\hat{b}$ referred by the committee to its own ideal point $\left(x_{f}=0\right)$ along the ideological dimension, because valence is transferable and amendments are costless. The committee can do nothing to change the outcome in the ideological dimension, so its incentive to invest is determined only by valence benefits, which are simply the expected return of the investment $E[v]$. The cutpoint for the cost of investment is thus $c_{o}^{t}\left(x_{c}\right)=E[v]$.

In summary, if valence is transferable, then under an open rule committee behavior and policy outcomes are as follows. (1) The committee invests if and only if the cost of investing is sufficiently low, i.e., $c \leq c_{o}^{t}\left(x_{c}\right)=E[v]$. (2) If the committee does not invest, the policy outcome is $(0,0)$. (3) If the committee invests and the investment returns valence $\tilde{v}$, the policy outcome is $(\tilde{v}, 0)$.

Closed Rule. Under a closed rule with transferable valence, our model is a straightforward variant of a RomerRosenthal agenda-setter game. In the final stage, the committee has referred a bill $\hat{b}=(\hat{v}, \hat{x})$ and the floor accepts the bill if and only if $\hat{v} \geq \bar{v}(\hat{x}, q)$, the valence cutoff from equation (1) such that the floor is at least as well off as under the status quo.

We now focus on the penultimate stage. Under an open rule, valence transferability allowed the floor to expropriate any valence generated in committee for its own policy ends, so the committee could not exert informal agenda power with high-valence policies. In contrast, with the formal protection of a closed rule, the ability to transfer valence across policies is retained solely by the committee. Thus, after observing the realized level of valence, the committee can alter the bill's ideological location to leave the floor indifferent between the referred bill and the status quo.

Formally, for each realization of valence $\tilde{v}$, the committee transfers the valence to the best ideological policy, for itself, that leaves the floor at least as well off as with the status quo. If the realized valence is sufficiently high, i.e., $\tilde{v} \geq \bar{v}\left(x_{c} ; q\right)$, the committee is able to implement its own ideal point. Otherwise, the farthest it can pull policy, while still getting the floor's approval, is $\bar{x}(\tilde{v} ; q)=\lambda_{f}^{-1}\left(\lambda_{f}(q)+\tilde{v}\right)$. The committee's optimal bill is $\hat{b}=(\tilde{v}, \hat{x})$, where $\hat{x} \equiv \min \left\{x_{c}, \bar{x}(\tilde{v} ; q)\right\}$.

The closed-rule equilibrium is shown in Figure 1, which graphs ideological policy outcomes as a function of the valence realization. For a low $\tilde{v}$ the committee proposes a policy on the ideological dimension that traces out the floor's indifference curve through the status quo policy $(0, q)$. For a high realization of valence, the committee proposes its own ideal point $x_{c}$ and the floor strictly prefers the committee's proposal over $(0, q)$. The floor only enjoys the benefits of valence utility when valence is sufficiently high to sate the committee's desire to extract ideological policy rents.

If the committee invests in valence, its expected utility is $E[v]-\int_{0}^{\bar{v}\left(x_{c} ; q\right)} \lambda_{c}\left(x_{c}-\bar{x}(v ; q)\right) f(v) d v$. If it does not invest, policy is gridlocked at $q$ and its utility is $-\lambda_{c}\left(x_{c}-\right.$ q). Subtracting the latter from the former, we derive the cost cutpoint determining the incentive to invest:

$$
\begin{aligned}
c_{c l}^{t}\left(x_{c}, q\right) \equiv & E[v]+\int_{0}^{\bar{v}\left(x_{c} ; q\right)}\left(\lambda_{c}\left(x_{c}-q\right)\right. \\
& -\lambda_{c}\left(x_{c}-\bar{x}(v ; q)\right) f(v) d v \\
& +\left(1-F\left(\bar{v}\left(x_{c} ; q\right)\right)\right) \lambda_{c}\left(x_{c}-q\right) .
\end{aligned}
$$

The first term in this expression is the value of the valence itself, which is the same as in the open-rule case. The second and third terms represent the ideological benefits that the committee achieves by using valence as leverage to pull policy toward its own ideal point. It is important to note that because of this ideological gain, the committee has a greater incentive to invest in expertise under a closed rule than under an open rule, i.e., $c_{c l}^{t}\left(x_{c}, q\right)=c_{o}^{t}\left(x_{c}\right)=E[v]$.

In summary, if valence is transferable, then under a closed rule committee behavior and policy outcomes are as follows. (1) The committee invests if and only if the cost of investing is sufficiently low, i.e., $c \leq c_{c l}^{t}\left(x_{c}, q\right)$. (2) If the committee does not invest, the policy outcome 


\section{FIgURE 1 Closed-Rule Outcome with Transferable Valence}

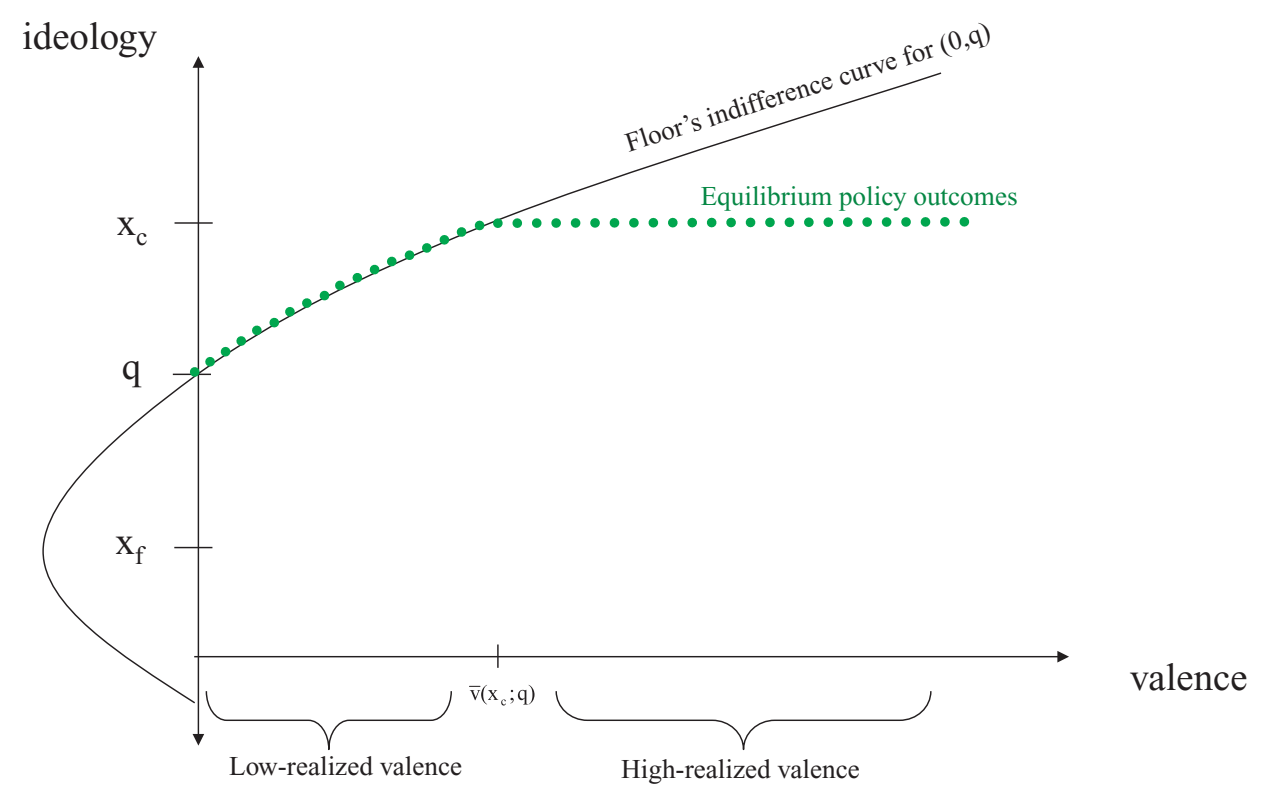

is $(0, q)$. (3)If the committee invests and the investment returns valence $\tilde{v}$, the policy outcome is $(\tilde{v}, \hat{x})$, where $\hat{x} \equiv \min \left\{x_{c}, \bar{x}(\tilde{v} ; q)\right\}$.

Rule Choice. If the floor's rule choice does not affect the committee's investment decision, the floor prefers an open rule because it receives its own ideal point along the ideology dimension and valence utility at least as high as under a closed rule.

However, as is the case for some parameter values in the Gilligan and Krehbiel model, in our transferable valence game, for intermediate costs of specialization the committee invests if and only if it receives a closed rule. ${ }^{12}$ We now solve for the floor's optimal rule choice in such cases, i.e., when $c \in\left(c_{o}^{t}\left(x_{c}\right), c_{c l}^{t}\left(x_{c}, q\right)\right]$. The floor's expected utility under a closed rule is

$$
\begin{aligned}
& -\int_{0}^{\bar{v}\left(x_{c} ; q\right)} \lambda_{f}(q) f(v) d v \\
& \quad+\int_{\bar{v}\left(x_{c} ; q\right)}^{\infty}\left(v-\lambda_{f}\left(x_{c}\right)\right) f(v) d v .
\end{aligned}
$$

\footnotetext{
${ }^{12}$ As an aside, note that in Gilligan and Krehbiel (1987) the floor may sometimes prefer a restrictive rule even if the rule choice is not pivotal for the committee's investment decision. However, this requires that the committee's preferences be closely aligned with the floor. In that model, the closed rule not only provides the committee with ideological rents but also is more informationally efficient, i.e., the value of the collective benefit itself is greater under the closed rule. This feature does not extend to our model.
}

Equation (4) has two components. When the valence realization is below $\bar{v}\left(x_{c} ; q\right)$, the floor enjoys no valence benefits because the committee extracts them all in the form of ideological policy rents. The floor is forced to accept a policy no better than the status quo, resulting in utility $-\lambda_{f}(q)$. However, when the valence realization is above $\bar{v}\left(x_{c} ; q\right)$, the committee extracts no additional ideological rents (it receives its own ideal point and is sated), and the floor enjoys the extra benefits of valence, i.e., $v-$ $\lambda_{f}\left(x_{c}\right)$ is strictly greater than $-\lambda_{f}(q)$. Because the floor's utility under an open rule absent investment is simply 0 , the floor prefers a closed rule with investment to an open rule with no investment if and only if equation (4) is positive.

If the committee's ideal point is exactly at the status quo $x_{c}=q$, equation (4) equals $E[v]-\lambda_{f}(q)$, the expected value of the valence return minus the floor's utility loss of accepting the noncentrist status quo point $q$. Also, equation (4) is strictly decreasing in $x_{c}$ and approaches $-\lambda_{f}(q)<0$ as $x_{c} \rightarrow \infty$ (Lemma 3 in the appendix). Intuitively these properties are obvious; a more extreme committee is less easily sated, so under a closed rule it leaves the floor with less surplus valence utility. In the limit, an infinitely extreme committee extracts all valence benefits in the form of ideological policy rents, leaving the floor no better off than with the status quo.

Thus, the floor's equilibrium rule choices are straightforward. If the status quo $q$ is sufficiently extreme, i.e., 


\section{FIGURE 2 Investment Decisions and Outcomes with Transferable Valence}

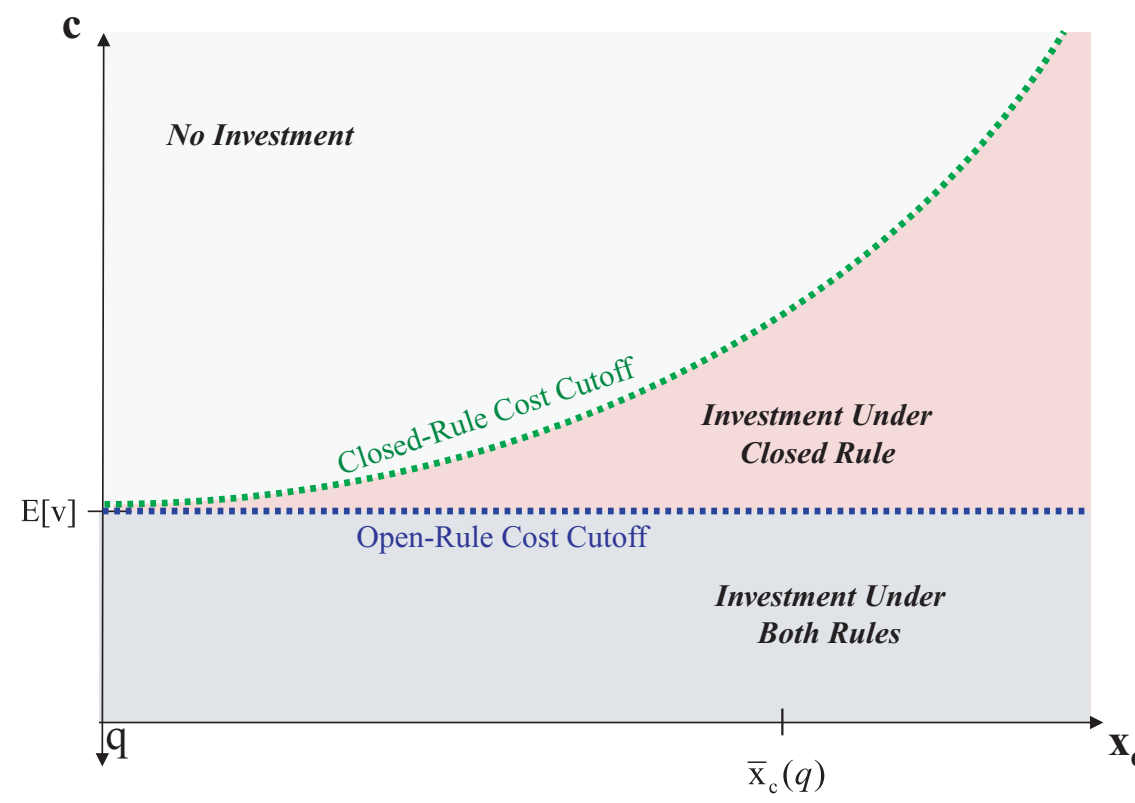

Open-Rule Cost Cutoff is $\mathrm{c}_{\mathrm{o}}^{\mathrm{t}}\left(\mathrm{x}_{\mathrm{c}}\right)$

Closed-Rule Cost Cutoff is $\mathrm{c}_{\mathrm{cl}}^{\mathrm{t}}\left(\mathrm{x}_{\mathrm{c}}, \mathrm{q}\right)$

Floor selects an open rule i.f.f.c $\in\left(\mathrm{c}_{\mathrm{o}}^{\mathrm{t}}\left(\mathrm{x}_{\mathrm{c}}\right), \mathrm{c}_{\mathrm{cl}}^{\mathrm{t}}\left(\mathrm{x}_{\mathrm{c}}, \mathrm{q}\right)\right], \mathrm{q}<\mathrm{q}^{*}$, and $\mathrm{x}_{\mathrm{c}} \in\left(\mathrm{q}, \overline{\mathrm{x}}_{\mathrm{c}}(q)\right)$

$\lambda_{f}(q) \geq E[v]$, then regardless of the committee's ideal point the value of valence is insufficient to overcome the ideological loss resulting from a closed rule. Alternatively, if $q$ is relatively moderate, i.e., $\lambda_{f}(q)<E[v]$, there is an upper bound on the committee's ideal point $\bar{x}_{c}(q)>q$ such that the floor would find it worthwhile to grant a closed rule in order to induce specialization. Combining these observations, we now characterize the floor's optimal rule choice as a function of the committee's ideal point $x_{c}$ and the cost of investment, $c$. These equilibrium rule choices are shown in Figure 2.

Proposition 1. With transferable valence, the floor strictly prefers a closed rule to an open rule if and only if both of the following conditions hold.

(i) A closed rule will induce the committee to invest when it otherwise would not, i.e.,

$$
c \in\left(c_{o}^{t}\left(x_{c}\right), c_{c l}^{t}\left(x_{c}, q\right)\right]
$$

(ii) The valence benefit to the floor exceeds the ideological loss from the closed rule, i.e.,

$$
\begin{aligned}
& \int_{\bar{v}\left(x_{c} ; q\right)}^{\infty}\left(v-\lambda_{f}\left(x_{c}\right)\right) f(v) d v \geq \\
& \int_{0}^{\bar{v}\left(x_{c} ; q\right)} \lambda_{f}(q) f(v) d v \text {. This may equivalently } \\
& \text { be written as } \\
& \text { a. } q<q^{*}, \text { where } q^{*} \text { solves } \lambda_{f}\left(q^{*}\right)=E[v] \\
& \text { b. } x_{c} \in\left(q, \bar{x}_{c}(q)\right) \text {, where } \bar{x}_{c}(q) \text { solves } \\
& \quad-\int_{0}^{\bar{v}\left(\bar{x}_{c}(q) ; q\right)} \lambda_{f}(q) f(v) d v \\
& \quad+\int_{\bar{v}\left(\bar{x}_{c}(q) ; q\right)}^{\infty}\left(v-\lambda_{f}\left(\bar{x}_{c}(q)\right)\right) f(v) d v=0
\end{aligned}
$$

Overall, the results in this section closely parallel the results in Gilligan and Krehbiel (1987), despite the fact that we use a very different model of information. In both models, specialization is beneficial to both the floor and the committee. If the cost of investment is low, the committee always specializes regardless of the floor's rule choice. On the other hand, if the cost is high the committee never invests. For intermediate cost levels, the committee's decision about whether to specialize depends on the rule under which its bill will be considered.

However, as we show below, when valence is policyspecific, the nature of the equilibrium is dramatically 
different. This indicates that the threat of expropriation is a key factor driving the canonical results.

\section{Policy-Specific Valence}

We now analyze the case of policy-specific valence. In the transferable valence game, we did not characterize the committee's initial choice of a target policy $\tilde{x}$ because valence generated by the committee's investment could be freely transferred across policies. With policy-specific valence, however, the valence returned by the committee's investment $\tilde{v}$ is attached solely to the target policy, and if either the committee or the floor chooses to alter the ideology of the bill, the fruits of the committee's investment are lost.

The committee's choice of a target policy is therefore a critical component of its strategy. If it works on an extreme policy, its bill will only be enacted by the floor if a high valence return is realized, which occurs with low probability. However, if the committee chooses a moderate target policy, it potentially foregoes ideological rents, because for high valence returns the floor would be willing to enact a more extreme policy. We now characterize the committee's investment decisions, including its choice of a target policy. The committee's equilibrium behavior under an open rule can be treated as a special case of the closed rule, which we therefore analyze first.

Closed Rule. The final stage (floor vote) under a closed rule is identical to the transferable valence case. In the penultimate stage (committee proposal), note that for any valence realization $\tilde{v}$ the committee has no incentive to amend its bill $\hat{b}$ from the target policy $\tilde{x}$. Any alternative bill preferred by the committee will have 0 valence because valence is nontransferable. Because $q \in\left(0, x_{c}\right)$, such bills fail against the status quo. In contrast to our transferable valence model, with policy-specific valence the committee has no incentive to alter the bill after observing the valence realization, so the set of equilibrium ideological policy outcomes is binary. Either the status quo prevails (if $v<\bar{v}(\tilde{x} ; q)$ ), or the target policy $\tilde{x}$ prevails (if $v \geq \bar{v}(\tilde{x} ; q))$.

Proceeding backward to the investment decision and selection of the target policy, suppose that the committee has chosen to invest. The optimal target policy maximizes the committee's expected utility conditional on investment. Clearly the committee will not select a target policy $\tilde{x}<q$ or $\tilde{x}>x_{c}$ because it would be better off working on either $q$ or $x_{c}$. We denote the optimal target policy as $\tilde{x}^{c l}\left(x_{c}, q\right)$, which is

$$
\begin{aligned}
\tilde{x}^{c l}\left(x_{c}, q\right)= & \underset{\tilde{x} \in\left[q, x_{c}\right]}{\arg \max }\left\{-F(\bar{v}(\tilde{x} ; q)) \lambda_{c}\left(x_{c}-q\right)\right. \\
& -(1-F(\bar{v}(\tilde{x} ; q))) \lambda_{c}\left(x_{c}-\tilde{x}\right) \\
& \left.+\int_{\bar{v}(\tilde{x} ; q)}^{\infty} v f(v) d v\right\} .
\end{aligned}
$$

The first term of the maximand is the committee's ideological loss when the valence $\tilde{v}$ is insufficient to beat the status quo, which occurs with probability $F(\bar{v}(\tilde{x} ; q))$. The second term is the ideological loss when $\tilde{v}$ is sufficient to pass the target policy $\tilde{x}$, which is better for the committee than the status quo, but weakly worse than its own ideal point $x_{c}$. The third term is the committee's utility from valence. Note that this equals $(1-F(\bar{v}(\tilde{x} ; q)))$. $E[v \mid v \geq \bar{v}(\tilde{x}, q)]$, the probability that the target policy passes times the expected value of valence conditional on passage. This is strictly less than $E[v]$ because valence is lost when the floor chooses to maintain the status quo.

We now state our first result for the case of policyspecific valence, which characterizes the optimal target policy $\tilde{x}^{c l}\left(x_{c}, q\right)$ under a closed rule. The appendix has the proof of this result, as well as others not proved in the main text.

Lemma 1. When valence is policy-specific, if the committee chooses to invest its optimal closed-rule target policy $\tilde{x}^{c l}\left(x_{c}, q\right)$ is unique, strictly interior to $\left[q, x_{c}\right]$, and strictly increasing in $q$.

We now turn to the committee's equilibrium investment decision. When the committee chooses not to invest, the status quo prevails, and its utility is $-\lambda_{c}\left(x_{c}-\right.$ $q)$. When it invests, its expected utility is the maximum of equation (5). To derive the cost cutpoint for investment, $c_{c l}^{n t}\left(x_{c}, q\right)$, we substitute the optimum $\tilde{x}^{c l}\left(x_{c}, q\right)$ into equation (5) and subtract $-\lambda_{c}\left(x_{c}-q\right)$.

$$
\begin{aligned}
& c_{c l}^{n t}\left(x_{c}, q\right) \equiv\left(1-F\left(\bar{v}\left(\tilde{x}^{c l}\left(x_{c}, q\right) ; q\right)\right)\right)\left[\lambda_{c}\left(x_{c}-q\right)\right. \\
& \left.-\lambda_{c}\left(x_{c}-\tilde{x}^{c l}\left(x_{c}, q\right)\right)\right]+\int_{\bar{v}\left(\tilde{x}^{c l}\left(x_{c}, q\right) ; q\right)}^{\infty} v f(v) d v
\end{aligned}
$$

In summary, if valence is policy-specific, then under a closed rule committee behavior and policy outcomes are as follows. (1) The committee invests if and only if the cost of investing is sufficiently low, i.e., $c \leq c_{c l}^{n t}\left(x_{c}, q\right)$. (2) If the committee does not invest, the policy outcome is $(0, q) .(3)$ If the committee invests and the investment returns valence $\tilde{v}$, the policy outcome is $\left(\tilde{v}, \tilde{x}^{c l}\left(x_{c}, q\right)\right)$ if $\tilde{v} \geq \bar{v}\left(\tilde{x}^{c l}\left(x_{c}, q\right) ; q\right)$ and $(0, q)$ otherwise. 
Open Rule. We now characterize the committee's investment behavior under an open rule. To simplify the analysis, we first show that in the policy-specific valence game the open-rule subgame can be solved as a special case of the closed-rule subgame with $q=0$, because both subgames result in the same policy outcome after every possible bill referral by the committee.

Lemma 2. If valence is policy-specific, then equilibrium expected payoffs for every investment decision and choice of target policy by the committee are identical between an open rule subgame and a closed-rule subgame with $q=0$.

Applying the lemma, we can substitute $q=0$ into the closed-rule results to derive the committee's investment behavior under an open rule. Recall that the optimal open-rule target policy is $\tilde{x}^{o}\left(x_{c}\right)$. For simplicity, we write the valence cutoff $\bar{v}(x ; 0)$ as $\bar{v}(x)=\lambda_{f}(x)$. Following equation (5),

$$
\begin{aligned}
\tilde{x}^{o}\left(x_{c}\right)= & \underset{x \in\left[0, x_{c}\right]}{\arg \max }\left\{-F(\bar{v}(x)) \lambda_{c}\left(x_{c}\right)-(1-F(\bar{v}(x)))\right. \\
& \left.\times \lambda_{c}\left(x_{c}-x\right)+\int_{\bar{v}(x)}^{\infty} v f(v) d v\right\} .
\end{aligned}
$$

We now state a corollary to Lemma 1 for the openrule case, and compare the closed- and open-rule target policies.

Proposition 2. With policy-specific valence, if the committee chooses to invest under an open rule, its optimal target policy $\tilde{x}^{o}\left(x_{c}\right)$ is unique and strictly interior to $\left[0, x_{c}\right]$. Moreover, $\tilde{x}^{o}\left(x_{c}\right)<\tilde{x}^{c l}\left(x_{c}, q\right)$ for all $q>0$.

Proof. The first statement follows trivially from the fact that $\tilde{x}^{o}\left(x_{c}\right)=\tilde{x}^{c l}\left(x_{c}, 0\right)$, while the second follows from the fact that $\tilde{x}^{c l}\left(x_{c}, q\right)$ is strictly increasing in $q$, as shown in Lemma 1.

Intuitively we would expect the target policy under an open rule to be more moderate than that under a closed rule; the proposition demonstrates formally that this holds for any status quo point $q>0$. Later, we will show that this is one factor that ensures that the floor prefers an open rule when valence is policy-specific.

Finally, as in the closed-rule case we subtract off $-\lambda_{c}\left(x_{c}\right)$, the committee's utility if it chooses not to invest and the floor passes its own ideal point, from the maximum of equation (7) and derive the open-rule cost cutpoint $c_{o}^{n t}\left(x_{c}\right)$ for committee investment:

$$
\begin{aligned}
c_{o}^{n t}\left(x_{c}\right) \equiv & \left(1-F\left(\bar{v}\left(\tilde{x}^{o}\left(x_{c}\right)\right)\right)\right)\left[\lambda_{c}\left(x_{c}\right)\right. \\
& \left.-\lambda_{c}\left(x_{c}-\tilde{x}^{o}\left(x_{c}\right)\right)\right]+\int_{\bar{v}\left(\tilde{x}^{o}\left(x_{c}\right)\right)}^{\infty} v f(v) d v .
\end{aligned}
$$

In summary, if valence is policy-specific, then under a closed rule committee behavior and policy outcomes are as follows. (1) The committee invests if and only if the cost is sufficiently low, i.e., $c \leq c_{o}^{n t}\left(x_{c}\right)$. (2) If the committee does not invest, the policy outcome is $(0,0)$. (3) If the committee does invest and the investment returns valence $\tilde{v}$, the policy outcome is $\left(\tilde{v}, \tilde{x}^{o}\left(x_{c}\right)\right)$ if $\tilde{v} \geq \bar{v}\left(\tilde{x}^{o}\left(x_{c}\right)\right)$ and $(0,0)$ otherwise.

Rule Choice. The rule chosen by the floor depends on two factors: the policy outcomes that prevail and the committee's incentive to invest under each type of rule. In the transferable valence game, the floor sometimes faced a trade-off in which it had to adopt a closed rule and sacrifice ideological rents to give the committee sufficient incentives to invest. For policy-specific valence, no such trade-off exists. We prove that open rules not only generate more moderate policy outcomes (Proposition 2), but also create greater incentives for the committee to invest.

Proposition 3. If valence is policy-specific, then $c_{c l}^{n t}\left(x_{c}\right.$, $q)<c_{o}^{n t}\left(x_{c}\right)$ for all $q>0$. For any cost $c \in\left(c_{c l}^{n t}\left(x_{c}, q\right)\right.$, $\left.c_{o}^{n t}\left(x_{c}\right)\right]$, the committee will invest under an open rule, but not under a closed rule.

Why do the beneficial incentive effects of closed rules vanish? When valence is policy-specific, a high valence return makes the committee's chosen target policy more attractive to the floor, but has no effect on the quality of the other available policy alternatives. As a result, the committee retains the ability to exert informal agenda power absent formal procedural rights. Regardless of the rule, the floor must accept the committee's target policy to enjoy the fruits of its valence return. This severs the link between restrictive rules and valence-driven agenda power, and they become substitutable means for achieving the same end.

Mathematically, a closed rule allows the committee to hold policy at the status quo $q>0$. Because utility is concave in the ideological dimension, the committee's ideological benefits from pulling policy in its direction from $q$ by a fixed increment $\delta$ are smaller than the benefits of pulling policy away from $x_{f}=0$ by that same $\delta$. Also, when policy begins at $q>0$ rather than the floor's ideal point, the floor is less easily persuaded (i.e., needs to see higher valence returns) to agree to move policy by $\delta$ toward the committee's ideal point. Consequently, the committee's utility benefits from exercising informal agenda power with valence are greater under an open rule.

The better incentive properties of the open rule, combined with the more moderate policy outcomes it generates (Proposition 2) together imply that the floor has an unconditional preference for open rules when valence 
is policy-specific, a striking contrast with Gilligan and Krehbiel's results.

Proposition 4. With policy-specific valence, the floor selects an open rule for all values of $c, q$, and $x_{c}$.

Given our previous results, the formal argument underlying this proposition is almost trivial. When the cost of investment is either low or high, the floor's rule decision has no effect on the committee's decision to invest, and hence the floor prefers the more moderate policy produced by an open rule. When the cost of investment is intermediate, from Proposition 3 we know that the committee invests in valence only under an open rule. Then under an open rule the outcome is either the floor's ideal point $x_{f}=0$ with no valence, or a bill $\left(\tilde{v}, \tilde{x}^{o}\left(x_{c}\right)\right)$ that is even better for the floor. In either case the floor is better off than under a closed rule, which guarantees that it receives the status quo policy $q$ with no valence.

\section{Application: Committee Composition}

Having analyzed rule choice, we briefly analyze committee membership. Gilligan and Krehbiel's prediction that the floor would choose centrist committees produced much empirical debate (e.g., Hall and Grofman 1990; Krehbiel 1991; Londregan and Snyder 1994). In our model, unlike Gilligan and Krehbiel's work, a floor may prefer to appoint preference outliers to committees. Although the floor would like to have a centrist committee that exerts effort to produce high-quality centrist legislation, it knows that if the cost of specialization is high, a centrist committee will be unwilling to specialize. In such cases the floor may choose to appoint outliers who place a higher value on informal agenda power and thus are more willing to specialize.

The fact that extreme committees place a high value on informal agenda power follows directly from risk aversion. To see this, suppose that a committee with quadratic preferences and ideal point $x_{c}>0$ faces the choice of accepting the policy outcome 0 , or paying a price $c>0$ to move policy to $x \in\left(0, x_{c}\right)$ with probability $p$. The committee's willingness to pay for this option is

$$
\begin{aligned}
& \left((1-p)\left(-\left(x_{c}-0\right)^{2}\right)+p\left(-\left(x_{c}-x\right)^{2}\right)\right) \\
& -\left(-\left(x_{c}-0\right)^{2}\right)=-p x^{2}+(2 p x) \cdot x_{c} .
\end{aligned}
$$

Note that this expression is increasing in the committee's ideal point, due to concavity of its utility function. This is the basic reason that a more extreme committee is willing to pay a higher cost to generate valence that can be used to pull policy toward its ideal point.

To see how the committee's investment incentives affect the floor's decision about whether to appoint a centrist or an outlier committee, we briefly consider the following special case of an extension to our model. ${ }^{13}$ Assume that the players have quadratic loss functions $\lambda_{f}(d)=\lambda_{c}(d)=d^{2}$, valence is exponentially distributed with density $f(v)=e^{-v}$, and the status quo is $q=\frac{1}{2}$. Suppose that prior to the game the floor, which has an ideal point at 0 , can select the ideal point of the committee, $x_{c}$, from the set $\left\{0, \frac{3}{4}, \frac{3}{2}\right\}$. What $x_{c}$ would it choose?

Transferable Valence. If valence is transferable, then the floor only appoints an outlier $x_{c}>0$ if it plans to use a closed rule to induce specialization. By Proposition 1, the committee's preferences thus cannot be too extreme, i.e., $x_{c} \leq \bar{x}_{c}(q)$. Given our simplifying assumptions, the most extreme committee to which the floor is willing to grant a closed rule is $\bar{x}_{c}(q)=\sqrt{q^{2}-\ln \left(q^{2}\right)} \approx 1.28$ for $q=\frac{1}{2}$. So in this example, the floor would be willing to appoint the moderate outlier $x_{c}=\frac{3}{4}$ if necessary to induce specialization, but would never appoint the extreme outlier $x_{c}=\frac{3}{2}$.

The optimal appointee depends on the cost of specialization, because as cost increases the committee must be more extreme to find specialization worthwhile. If the cost is intermediate, e.g., $c=1.04$, the floor optimally appoints the moderate outlier $x_{c}=\frac{3}{4}$ because it will specialize, but a centrist committee $x_{c}=0$ would not. Alternatively, if the cost of specialization is high, e.g., $c=1.1$, the floor chooses the centrist committee $x_{c}=0$, expecting no specialization to occur. Although the extreme outlier $x_{c}=\frac{3}{2}$ would specialize if granted a closed rule, the resulting distributive costs are too great for the floor to be willing to grant a closed rule.

Policy-Specific Valence. If valence is policy-specific, the floor will always use an open rule and thus is always better off appointing an outlier committee that will specialize over a centrist one that will not. If the floor appoints an outlier that fails to produce enough valence $\tilde{v}$ on its target policy $\tilde{x}^{o}\left(x_{c}\right)$ to leave the floor better off than with its own ideal point $x_{f}=0$, the floor can simply amend the policy and be no worse off.

The committee's target policy $\tilde{x}^{o}\left(x_{c}\right)$ is strictly increasing in its ideal point: $\tilde{x}^{o}\left(\frac{3}{4}\right) \approx .448$ and $\tilde{x}^{o}\left(\frac{3}{2}\right) \approx$ .560. The floor therefore desires to appoint the most

\footnotetext{
${ }^{13}$ A complete analysis of the design of committees is in the supplemental appendix.
} 
moderate committee willing to specialize. If the cost of specialization is intermediate, e.g., $c=1.2>E[v]=1$, the floor appoints the moderate outlier $x_{c}=\frac{3}{4}$ because both outliers would specialize but the centrist committee would not. If the cost of specialization is high, e.g., $c=$ 1.5 , the floor must appoint the extreme outlier $x_{c}=\frac{3}{2}$ to ensure specialization.

In summary, the example demonstrates that with either type of valence the floor may prefer to have noncentrist committees. The most important implication of this section is that the widely held intuition (starting with Gilligan and Krehbiel 1990; Krehbiel 1991) that models of expertise and information provision imply a floor preference for centrist committees is not general; rather, that intuition is specific to the private-information models used by those authors. In our model, as in previous informational models, the congressional committee system is designed to produce high-quality legislation. The difference is that in our model, the parent chamber can have an incentive to construct committees composed of preference outliers.

\section{Robustness}

In this section, we discuss how our key results extend to alternative model specifications, starting with technical features and then considering more substantial changes to our theoretical approach.

At a technical level, the structure of the utility functions for the two players in our model can be generalized, because they are constrained neither to weight ideology against valence in a particular proportion nor to place the same relative weight on valence. Also, our analysis does not require symmetry on the spatial component of utility functions. More generally, in the transferable valence game, the results hold for certain types of interactions between ideology and valence, including arbitrary utility functions $U_{f}(v, x)$ and $U_{c}(v, x)$ that are strictly increasing in $v$ for any $x$, strictly single peaked in $x$ for any $v$, and have the same peak $x_{i}$ for any $v$. In the nontransferable valence game, a sufficient condition for our key results is that the utility functions can be written as $U_{i}(v, x)=$ $g_{i}(v)+h_{i}(x)$, with $g_{i}$ increasing and $h_{i}$ strictly concave for both players.

More importantly, the key result in our policyspecific valence model does not hinge on the sharp discontinuity implied by fully policy-specific valence: it can be extended to the case of partially transferable valence, provided that valence is not too transferable. For example, assume a continuous valence decay function $g(\tilde{v},|\tilde{x}-x|)$. In this specification, the level of valence associated with the target policy $\tilde{x}$ is $\tilde{v}$, and the function $g(\cdot, \cdot)$ specifies the amount of valence remaining when the bill is amended to an alternative policy $x .{ }^{14}$ The negative incentive effects from closed rules remain, provided that $g^{2}(\cdot, \cdot)$, the first derivative of valence with respect to movements in the ideology dimension away from the target policy, is sufficiently negative. In fact, when $\left|g^{2}(\cdot, \cdot)\right|>\lambda_{f}^{\prime}\left(x_{c}\right)$, the result not only remains but the formal analysis is identical. The intuition is straightforward: if valence is only transferable to policies very close to the initial target policy $\tilde{x}$, then under an open rule the floor makes only very small changes to the committee referral, because the marginal valence loss quickly exceeds the marginal ideological benefit.

Finally, and most importantly, we can use our model to analyze what happens if the committee, but not the floor, can transfer valence, so that although valence is transferable it is inherently nonexpropriable. Such a setup is natural if expertise in a policy area consists of skill in drafting legislation that will survive legal challenges and be implemented properly by administrative agencies. Although the polar cases we have analyzed - valence transferable by either actor or by neither actor-are appropriate for many issue areas, such as health care reform, there surely are other policy areas in which valence is transferable by the committee but not by the floor. Analysis of a model with this sort of valence yields results similar to the ones we present here for policy-specific valence: the floor always chooses open rules, which are more effective than closed rules in inducing the committee to invest in expertise. Details can be found in the supplemental appendix.

\section{Conclusion}

To conclude, we revisit our key contributions and discuss their implications in greater depth. For the past two decades, the Crawford and Sobel (1982) model has been so influential that formal theorists' notions of good public policy have been, with very few exceptions, based on uncertainty reduction in models of incomplete information. Despite the many advances such work has produced, we believe that it is a mistake for scholars collectively to lock in to a single modeling technology, particularly given that for many empirical applications a valence-based model is more natural than the $x=p+\omega$ setup.

To demonstrate the utility of our approach, we tackle a question that is largely infeasible in the standard

\footnotetext{
${ }^{14}$ This setup is related to Callander's (2008) Brownian motion model, which formalizes the intuition that actors' expected utility declines as policy is shifted away from previously developed options.
} 
model-the effect of information transferability on procedural choice. As noted in the introduction and in our discussion of information expropriability, for many types of policies, particularly those that require careful coordination of many components of a complicated piece of legislation, information that is gathered to craft one bill cannot be readily applied to other bills elsewhere in the ideological spectrum.

When valence is transferable, our results are quite similar to Gilligan and Krehbiel's (1987). This fact has two implications. At a technical level, Gilligan and Krehbiel's results on legislative procedures are more general than previously understood, because they can be obtained in a model of information as transferable valence as well as in a model of information as private knowledge of $\omega$. However, at an applied level, many scholars implicitly assume that results from the $x=p+\omega$ setup apply to any type of policy-relevant information. This interpretation simply is not correct, because Gilligan and Krehbiel's results hinge on the fact that a restrictive rule is necessary to prevent the floor from expropriating the committee's investment. In sharp contrast, in our model with policy-specific information, the committee's investment is protected by the nature of the information itself. As a result, open rules are superior for inducing committee effort, because they give the committee a greater incentive to obtain informal agenda power by crafting a well-designed, high-valence proposal that the floor is willing to enact. A comparison of our two models suggests a new testable prediction for future empirical research: committees are more likely to operate under restrictive rules when the nature of their expertise is transferable than when it is policy-specific.

Finally, we note that there are many possible theoretical extensions of our framework for studying specialization and expertise. Here we note three possibilities. First, the model could be used to analyze situations in which legislation can be developed by multiple committees, factions within a committee, or outside lobbyists. The natural question that arises in such a model is whether the multiple actors who can engage in policy development will free-ride on each other's efforts or engage in an arms race to produce high-valence policies at different ideological locations. Second, as suggested by our colleague John Hatfield, the model could be extended to allow a committee to choose whether to invest in transferable or policy-specific expertise. This variant would capture the intuition that a committee's decision to collect general or policy-specific information is affected by strategic considerations of policy influence. In particular, the ability to use policyspecific information to exert informal agenda power may inefficiently distort a committee's informational investments in this direction. Third, the model could be used to analyze how other features of legislative institutions, such as the filibuster, affect the quality of policies that are enacted. Ultimately, we hope that others will build upon our model to analyze other aspects of legislative organization and political processes more generally.

\section{Appendix}

Let $V_{c l}^{t}\left(q, x_{c}\right), V_{o}^{t}\left(x_{c}\right), V_{c l}^{n t}\left(q, x_{c}\right)$, and $V_{o}^{n t}\left(x_{c}\right)$ denote the floor's equilibrium utility when the committee invests-subscripts refer to the rule (closed or open) and superscripts refer to the type of valence (transferable or nontransferable). Now define the function $V(q, x)$ as follows. For $x \in[0, q], V(q, x)=$ $E[v]-\lambda_{f}(x)$. For $x \in(q, \infty), V(q, x)=\int_{0}^{\bar{v}(x ; q)}-\lambda_{f}$ (q) $f(v) d v+\int_{\bar{v}(x ; q)}^{\infty}\left(v-\lambda_{f}(x)\right) f(v) d v$.

Lemma 3. $V(q, x)$ has the following properties.

(i) The floor's equilibrium utility if the committee invests can be expressed in terms of $V(\cdot)$, because $V_{c l}^{t}\left(q, x_{c}\right)=V\left(q, x_{c}\right), V_{o}^{t}\left(x_{c}\right)=V(0$, $0)=E[v], V_{c l}^{n t}\left(q, x_{c}\right)=V\left(q, \tilde{x}^{c l}\left(x_{c}, q\right)\right)$, and $V_{o}^{n t}\left(q, x_{c}\right)=V\left(0, \tilde{x}^{c l}\left(x_{c}, 0\right)\right)$.

(ii) $V(q, x)$ is continuous in $q$ and $x_{c}$.

(iii) $V(q, x)$ is strictly decreasing in $x$ and $\lim _{x \rightarrow \infty}$ $V(q, x)=-\lambda_{f}(q)$.

(iv) $V(q, x)$ is strictly decreasing in $q$ for $q \in[0, x]$.

Proof. Property 1 is straightforward to verify and 2 follows from continuity of $\lambda_{f}(\cdot)$ and $\lambda_{c}(\cdot)$.

Property 3: First we show strictly decreasing. Clearly the property holds for $x \leq q$. Now consider $q<x<x^{\prime}$, which implies $\bar{v}(x ; q)<\bar{v}\left(x^{\prime} ; q\right)$. Then we have

$$
\begin{aligned}
V(q, x)= & \int_{0}^{\bar{v}(x ; q)}-\lambda_{f}(q) f(v) d v \\
& +\int_{\bar{v}(x ; q)}^{\bar{v}\left(x^{\prime} ; q\right)}\left(v-\lambda_{f}(x)\right) f(v) d v \\
& +\int_{\bar{v}\left(x^{\prime} ; q\right)}^{\infty}\left(v-\lambda_{f}(x)\right) f(v) d v
\end{aligned}
$$

and

$$
\begin{aligned}
V\left(q, x^{\prime}\right)= & \int_{0}^{\bar{v}(x ; q)}-\lambda_{f}(q) f(v) d v \\
& +\int_{\bar{v}(x ; q)}^{\bar{v}\left(x^{\prime} ; q\right)}-\lambda_{f}(q) f(v) d v \\
& +\int_{\bar{v}\left(x^{\prime} ; q\right)}^{\infty}\left(v-\lambda_{f}\left(x^{\prime}\right)\right) f(v) d v
\end{aligned}
$$


which implies

$$
\begin{aligned}
& V(q, x)-V\left(q, x^{\prime}\right) \\
& =\int_{\bar{v}(x ; q)}^{\bar{v}\left(x^{\prime} ; q\right)}\left(\left(v-\lambda_{f}(x)\right)-\left(-\lambda_{f}(q)\right)\right) f(v) d v \\
& \quad+\int_{\bar{v}\left(x^{\prime} ; q\right)}^{\infty}\left(\lambda_{f}\left(x^{\prime}\right)-\lambda_{f}(x)\right) f(v) d v>0 .
\end{aligned}
$$

In the first term $v-\lambda_{f}(x) \geq-\lambda_{f}(q)$ because $v \geq \bar{v}(x ; q)$. In the second term $\lambda_{f}\left(x^{\prime}\right)>\lambda_{f}(x)$ because $x^{\prime}>x$.

Now we show $\lim _{x \rightarrow \infty} V(q, x)=-\lambda_{f}(q)$. Clearly $\lim _{x \rightarrow \infty} V(q, x) \geq-\lambda_{f}(q)$ since $V(q, x)>-\lambda_{f}(q) \forall x$. It hence suffices to show $\lim _{x \rightarrow \infty} V(q, x) \leq-\lambda_{f}(q)$. Since $-\lambda_{f}(x)<0$, we have

$$
\begin{aligned}
\lim _{x \rightarrow \infty} V(q, x) \leq & \lim _{x \rightarrow \infty}\left(\int_{0}^{\bar{v}(x ; q)}-\lambda_{f}(q) f(v) d v\right. \\
& \left.+\int_{\bar{v}(x ; q)}^{\infty} v f(v) d v\right) \\
= & \lim _{z \rightarrow \infty}\left(\int_{0}^{z}-\lambda_{f}(q) f(v) d v\right. \\
& \left.+\int_{z}^{\infty} v f(v) d v\right) \text { by } \bar{v}(x ; q) \\
& \text { increasing, convex in } x \\
= & -\lambda_{f}(q) .
\end{aligned}
$$

Property 4: Consider $q<q^{\prime}<x$, which implies $\bar{v}\left(x ; q^{\prime}\right)<\bar{v}(x ; q)$. Then

$$
\begin{aligned}
V & (q, x)-V\left(q^{\prime}, x\right) \\
& =\int_{0}^{\bar{v}\left(x ; q^{\prime}\right)}\left(\lambda_{f}\left(q^{\prime}\right)-\lambda_{f}(q)\right) f(v) d v \\
& +\int_{\bar{v}\left(x ; q^{\prime}\right)}^{\bar{v}(x ; q)}\left(-\lambda_{f}(q)-\left(v-\lambda_{f}(x)\right)\right) f(v) d v>0
\end{aligned}
$$

since $\lambda_{f}\left(q^{\prime}\right)>\lambda_{f}(q)$ and $-\lambda_{f}(q)>v-\lambda_{f}(x)$ for $v<$ $\bar{v}(x ; q)$.

Proof of Lemma 1. From equation (5), the committee's optimal choice satisfies

$$
\begin{aligned}
\tilde{x}^{c l}\left(x_{c}, q\right)= & \underset{x \in\left[q, x_{c}\right]}{\arg \max }\left\{-F(\bar{v}(x ; q)) \lambda_{c}\left(x_{c}-q\right)\right. \\
& -(1-F(\bar{v}(x ; q))) \lambda_{c}\left(x_{c}-x\right) \\
& \left.+\int_{\bar{v}(x ; q)}^{\infty} v f(v) d v\right\} .
\end{aligned}
$$

Recall $\bar{v}(x ; q)=\lambda_{f}(x)-\lambda_{f}(q)$. The derivative of the committee's objective function w.r.t. $x$ is

$$
\begin{aligned}
& (1-F(\bar{v}(x ; q)))\left(-H(\bar{v}(x ; q)) \cdot \lambda_{f}^{\prime}(x)\right. \\
& \cdot\left[\lambda_{c}\left(x_{c}-q\right)-\lambda_{c}\left(x_{c}-x\right)+\bar{v}(x ; q)\right] \\
& \left.+\lambda_{c}^{\prime}\left(x_{c}-x\right)\right),
\end{aligned}
$$

where $H(v)$ denotes the hazard rate $\frac{f(v)}{1-F(v)}$ and $\frac{\partial \bar{v}}{\partial x}=$ $\lambda_{f}^{\prime}(x)$. To show that the committee's optimal target policy is unique, strictly interior to $\left[q, x_{c}\right]$, and characterized by the first-order condition, it suffices to show that equation (9) (a) is strictly positive evaluated at $x=q$, (b) is strictly negative evaluated at $x=x_{c}$, and (c) crosses 0 exactly once.

First, note that equation (9) is the product of two terms, $(1-F(\bar{v}(x ; q)))$ and $Z\left(x, q, x_{c}\right)$, where

$$
\begin{aligned}
Z\left(x, q, x_{c}\right) \equiv- & H(\bar{v}(x ; q)) \cdot \lambda_{f}^{\prime}(x) \\
\cdot & {\left[\lambda_{c}\left(x_{c}-q\right)-\lambda_{c}\left(x_{c}-x\right)+\bar{v}(x ; q)\right] } \\
& +\lambda_{c}^{\prime}\left(x_{c}-x\right) .
\end{aligned}
$$

Since $(1-F(\bar{v}(x ; q)))>0, \forall x$ by full support of $f(v)$, equation (9) has the same sign as $Z\left(x, q, x_{c}\right)$, so it suffices to show properties (a), (b), and (c) for the latter.

To show (a), evaluating at $x=q, Z\left(q, q, x_{c}\right)=\lambda_{c}^{\prime}\left(x_{c}-\right.$ $q)>0$. To show (b), evaluating at $x=x_{c}$ and using the fact that $\lambda_{i}(0)=\lambda_{i}^{\prime}(0)=0, Z\left(x_{c}, q, x_{c}\right)=-H\left(\bar{v}\left(x_{c} ; q\right)\right)$. $\lambda_{f}^{\prime}\left(x_{c}\right) \cdot\left[\lambda_{c}\left(x_{c}-q\right)+\bar{v}\left(x_{c} ; q\right)\right]<0$.

To show (c) we show $Z\left(x, q, x_{c}\right)$ is strictly decreasing in $x$. Examining equation (10) term by term, it is straightforward to verify that the following observations imply this property: $(1) \bar{v}(x ; q)$ is strictly increasing in $x$ and hence, because $H(v)$ is assumed to be nondecreasing, $H(\bar{v}(x ; q))$ is nondecreasing in $x,(2)-\lambda_{c}\left(x_{c}-x\right)$ is strictly increasing in $x,(3) \lambda_{f}^{\prime}(x)$ is strictly increasing in $x$ by convexity, and (4) $\lambda_{c}^{\prime}\left(x_{c}-x\right)$ is strictly decreasing in $x$.

Finally, we show that $\tilde{x}^{c l}\left(x_{c}, q\right)$ is strictly increasing in $q$. First, observe that by the properties previously shown, $Z\left(x, q, x_{c}\right)>0$ implies that $\tilde{x}^{c l}\left(x_{c}, q\right)>x$. Thus, if we let $q<q^{\prime}$ we can show that the target policy is strictly increasing, i.e., $\tilde{x}^{c l}\left(x_{c}, q^{\prime}\right)>\tilde{x}^{c l}\left(x_{c}, q\right)$, by proving that $Z\left(\tilde{x}^{c l}\left(x_{c}, q\right), q, x_{c}\right)=0$ implies that $Z\left(\tilde{x}^{c l}\left(x_{c}, q\right), q^{\prime}, x_{c}\right)>0$. This holds because $Z\left(x, q, x_{c}\right)$ is strictly increasing in $q$, which can be seen from equation (10) due to the fact that $(1) \bar{v}(x ; q)$ is strictly decreasing in $q$, which implies $H(\bar{v}(x ; q))$ is weakly decreasing in $q$, and $(2) \lambda_{c}\left(x_{c}-q\right)$ is strictly decreasing in $q$.

Proof of Lemma 2. The initial choice of rule has no effect on the set of possible target policies, the expected distribution of postinvestment valence returns, or the set 
of feasible postinvestment bill referrals. Hence, it suffices to show that every postinvestment bill referral by the committee will result in the same final policy outcome when the floor behaves optimally in the final stage. This implies that the ex ante expected floor and committee payoffs for any investment decision and choice of target policy will be identical between the two subgames.

Consider an arbitrary bill referral $(\hat{v}, \hat{x})$. Under a closed rule with a status quo point $(0,0)$, the floor's choice set is restricted to $\{(0,0),(\hat{v}, \hat{x})\}$, where $(\hat{v}, \hat{x})$ is the committee's bill referral and may be different from the target policy with realized valence $(\tilde{v}, \tilde{x})$. Under an open rule, the floor may select from the full set $\{(0, y), \forall y \in \mathbb{R}\} \cup\{(\hat{v}, \hat{x})\}$. However, the floor's additional choices are irrelevant because $(0,0)$ dominates any $(0, y)$. Hence for any bill referral $(\hat{v}, \hat{x})$, the floor's final stage choice in either game is identical, demonstrating the result.

Proof of Proposition 3. Consider first the closed rule. Associated with $\tilde{x}^{c l}\left(x_{c}, q\right)$ is a valence cutpoint $\bar{v}\left(\tilde{x}^{c l}\left(x_{c}, q\right) ; q\right)$ such that $\tilde{x}^{c l}\left(x_{c}, q\right)$ prevails over the status quo whenever $\tilde{v} \geq \bar{v}\left(\tilde{x}^{c l}\left(x_{c}, q\right) ; q\right)$. Now let $y$ be the unique ideological location in the interval $\left(0, x_{c}\right)$ that satisfies $\bar{v}\left(\tilde{x}^{c l}\left(x_{c}, q\right) ; q\right)=\bar{v}(y ; 0)$. Recall $\bar{v}(y ; 0)$ is the valence cutoff under an open rule when the target policy is $y$ (by Lemma 2). Henceforth, we denote $\bar{v}(y ; 0)$ as $\bar{v}(y)$ for simplicity. So $y$ is the ideological point between the floor and committee ideal points such that, were the committee to select it as the target policy under an open rule, it would become the final policy outcome for the same realizations of valence as $\tilde{x}^{c l}\left(x_{c}, q\right)$ does under a closed rule. It is easy to verify that $y$ exists, is unique, and is in the interval $\left(0, x_{c}\right)$.

Now suppose that under an open rule the committee invests and works on target policy $y$. The utility from working on $y$ must be weakly less than the utility of working on $\tilde{x}^{o}\left(x_{c}\right)$ (because the latter is optimal), and combining this observation with equation (8), we have

$$
\begin{aligned}
c_{o}^{n t}\left(x_{c}\right) \geq & (1-F(\bar{v}(y)))\left[\lambda_{c}\left(x_{c}\right)-\lambda_{c}\left(x_{c}-y\right)\right] \\
& +\int_{\bar{v}(y)}^{\infty} v f(v) d v .
\end{aligned}
$$

Now subtract $c_{c l}^{n t}\left(x_{c}, q\right)$ in equation (6) from both sides, recalling that $\bar{v}\left(\tilde{x}^{c l}\left(x_{c}, q\right) ; q\right)=\bar{v}(y)$.

$$
\begin{aligned}
c_{o}^{n t}\left(x_{c}\right)-c_{c l}^{n t}\left(x_{c}, q\right) & \geq(1-F(\bar{v}(y)))\left(\left[\lambda_{c}\left(x_{c}\right)\right.\right. \\
& \left.-\lambda_{c}\left(x_{c}-y\right)\right]-\left[\lambda_{c}\left(x_{c}-q\right)\right. \\
& \left.\left.-\lambda_{c}\left(x_{c}-\tilde{x}^{c l}\left(x_{c}, q\right)\right)\right]\right) .
\end{aligned}
$$

Because $f(\cdot)$ has full support $(1-F(\bar{v}(y)))$ is strictly positive, so a sufficient condition for $c_{o}^{n t}\left(x_{c}\right)>c_{c l}^{n t}\left(x_{c}, q\right)$ is

$$
\begin{aligned}
\lambda_{c}\left(x_{c}\right)-\lambda_{c}\left(x_{c}-y\right) & >\lambda_{c}\left(x_{c}-q\right) \\
& -\lambda_{c}\left(x_{c}-\tilde{x}^{c l}\left(x_{c}, q\right)\right) .
\end{aligned}
$$

Equation (11) follows from convexity of $\lambda_{f}(\cdot)$ and $\lambda_{c}(\cdot)$. We show this in two steps. First we argue that $y>$ $\tilde{x}^{c l}\left(x_{c}, q\right)-q$.

$$
\begin{aligned}
\lambda_{f}\left(\tilde{x}^{c l}\left(x_{c}, q\right)\right)- & \lambda_{f}(q)=\bar{v}\left(\tilde{x}\left(x_{c}, q\right) ; q\right)=\bar{v}(y) \\
& =\lambda_{f}(y)<\lambda_{f}(y+q)-\lambda_{f}(q) .
\end{aligned}
$$

The last inequality follows from convexity of $\lambda_{f}(\cdot)$ and $\lambda_{f}(0)=0$. Equation (12) shows $\lambda_{f}\left(\tilde{x}^{c l}\left(x_{c}, q\right)\right)<$ $\lambda_{f}(y+q)$, implying $y+q>\tilde{x}^{c l}\left(x_{c}, q\right)$ since $\lambda_{f}(\cdot)$ is strictly increasing. We now use the fact that $y>$ $\tilde{x}^{c l}\left(x_{c}, q\right)-q$ to show the final result.

$$
\begin{aligned}
& \lambda_{c}\left(x_{c}\right)-\lambda_{c}\left(x_{c}-y\right) \\
& \quad>\lambda_{c}\left(x_{c}-q\right)-\lambda_{c}\left(x_{c}-(y+q)\right) \\
& \quad>\lambda_{c}\left(x_{c}-q\right)-\lambda_{c}\left(x_{c}-\tilde{x}^{c l}\left(x_{c}, q\right)\right) .
\end{aligned}
$$

The strict inequality in the first line follows from convexity of $\lambda_{c}(\cdot)$. The strict inequality at the start of the second line follows from the fact that $y+q>\tilde{x}^{c l}\left(x_{c}, q\right)$ and $\lambda_{c}(\cdot)$ is increasing.

Proof of Proposition 4. If $c>c_{o}^{n t}\left(x_{c}\right)$, the committee does not invest in valence under either rule, and the floor prefers an open rule. If $c \in\left(c_{c l}^{n t}\left(x_{c}, q\right), c_{o}^{n t}\left(x_{c}\right)\right]$, the committee invests only under an open rule. Under a closed rule the floor's utility is $-\lambda_{f}(q)<0$. Under an open rule, the floor's utility is at least as great as $0-\lambda_{f}(0)=0$ for any $\tilde{v}$, so it strictly prefers an open rule.

Finally, consider $c \leq c_{c l}^{n t}\left(x_{c}, q\right)$, which implies the committee invests in valence under both rules. We must show that $V_{c l}^{n t}\left(q, x_{c}\right)<V_{o}^{n t}\left(x_{c}\right)$.

$$
\begin{aligned}
& V_{c l}^{n t}\left(q, x_{c}\right)=V\left(q, \tilde{x}^{c l}\left(x_{c}, q\right)\right)<V\left(0, \tilde{x}^{c l}\left(x_{c}, q\right)\right) \\
& \quad \text { by parts } 1 \text { and } 4 \text { of Lemma } 3 \\
& <V\left(0, \tilde{x}^{c l}\left(x_{c}, 0\right)\right)=V_{o}^{n t}\left(x_{c}\right) \\
& \quad \text { by Lemma 1, and parts } 1 \text { and } 3 \text { of Lemma 3. }
\end{aligned}
$$

\section{References}

Aghion, Philippe, and Jean Tirole. 1997. "Formal and Real Authority in Organizations." The Journal of Political Economy 105(1): 1-29.

Ansolabehere, Stephen, and James M. Snyder Jr. 2000. "Valence Politics and Equilibrium in Spatial Election Models." Public Choice 103(3/4): 327-36.

Aragones, Enriqueta, and Thomas Palfrey. 2002. "Mixed Equilibrium in a Downsian Model with a Favored Candidate." Journal of Economic Theory 103(1): 131-61. 
Ashworth, Scott, and Ethan Bueno de Mesquita. 2009. "Elections with Platform and Valence Competition." Games and Economic Behavior 67(1): 191-216.

Austen-Smith, David. 1990. "Information Transmission in Debate." American Journal of Political Science 34(1): 124-52.

Baron, David P. 2000. "Legislative Organization with Informational Committees.” American Journal of Political Science 44(3): 485-505.

Battaglini, Marco. 2002. "Multiple Referrals and Multidimensional Cheap Talk.” Econometrica 70: 1379-1401.

Bendor, Jonathan, and Adam Meirowitz. 2004. "Spatial Models of Delegation." American Political Science Review 98(2): 293-310.

Caillaud, Bernard, and Jean Tirole. 2002. "Parties as Political Intermediaries." Quarterly Journal of Economics 117(4): 1453-89.

Callander, Steven. 2008. “A Theory of Policy Expertise.” Quarterly Journal of Political Science 3(2): 123-40.

Crawford, Vince, and Joel Sobel. 1982. "Strategic Information Transmission." Econometrica 50: 1431-51.

Diermeier, Daniel. 1995. "Commitment, Deference, and Legislative Institutions." American Political Science Review 89(2): 344-55.

Fenno, Richard F. 1973. Congressmen in Committees. Boston: Little, Brown.

Gilligan, Thomas W., and Keith Krehbiel. 1987. "Collective Decisionmaking and Standing Committees: An Informational Rationale for Restrictive Amendment Procedures." Journal of Law, Economics, and Organization 3(2): 287-335.

Gilligan, Thomas W., and Keith Krehbiel. 1990. "Organization of Informative Committees by a Rational Legislature.” American Journal of Political Science 34(2): 531-64.

Groseclose, Tim. 2001. "A Model of Candidate Location When One Candidate Has a Valence Advantage." American Journal of Political Science 45(4): 862-86.

Hall, Richard. 1996. Participation in Congress. New Haven, CT: Yale University Press.

Hall, Richard L., and Bernard Grofman. 1990. "The Committee Assignment Process and the Conditional Nature of Committee Bias." American Political Science Review 84(4): 1149-66.

Krehbiel, Keith. 1991. Information and Legislative Organization. Ann Arbor: University of Michigan Press.
Krehbiel, Keith. 2005. "Plausibility of Signals by a Heterogeneous Committee.” American Political Science Review 95(2): 453-57.

Krishna, Vijay, and John Morgan. 2005. "Asymmetric Information and Legislative Rules: Some Amendments." American Political Science Review 95(2): 435-52.

Lax, Jeffrey R., and Charles M. Cameron. 2007. "Bargaining and Opinion Assignment on the US Supreme Court.” Journal of Law, Economics, and Organization 23(2): 276-302.

Londregan, John B. 2000. Legislative Institutions and Ideology in Chile. Cambridge: Cambridge University Press.

Londregan, John, and James M. Snyder Jr. 1994. "Comparing Committee and Floor Preferences.” Legislative Studies Quarterly 19(2): 233-266.

Romer, Thomas, and Howard Rosenthal. 1979. "Bureaucrats versus Voters: On the Political Economy of Resource Allocation by Direct Democracy." Quarterly Journal of Economics 93(4): 563-587.

Ting, Michael M. 2011. “Organizational Capacity.” Journal of Law, Economics, and Organization. Forthcoming.

\section{Supporting Information}

Additional Supporting Information may be found in the online version of this article:

- Section 1 proves main substantive results hold if the valence of the status quo is strictly greater than zero.

- Section 2 provides a complete set of results for the committee composition game (these results are used to generate the example in the main text).

- Section 3 analyzes a variant of our model in which valence is transferable by the committee but not expropriable by the floor.

Please note: Wiley-Blackwell is not responsible for the content or functionality of any supporting materials supplied by the authors. Any queries (other than missing material) should be directed to the corresponding author for the article. 